\title{
The Development of Mental Health Learning Materials Using The Metacognitive Approach in Counseling Guidance Study Programme in FKIP UMSU
}

\author{
Jamilah $^{1, a}$, Sri Ngayomi Yudha Wastuti ${ }^{1, b}$, and Feri Haryati ${ }^{1, c^{*}}$ \\ ${ }^{1}$ Counseling Guidance Study Programme, Muhammadiyah University of North Sumatera, Medan, Indonesia \\ c feriharyati@umsu.ac.id \\ ${ }^{*}$ Corresponding Author \\ Whatsapp Number [ 085275726999 ]
}

How to Cite: Jamilah, Wastuti, S.,N.,Y, \& Haryati, F. (2019). The Development of Mental Health Learning Materials Using The Metacognitive Approach in Counseling Guidance Study Programme in FKIP UMSU. International Journal for Educational and Vocational Studies, 1(1), 62-67. doi: https://doi.org/10.29103/ijevs. v1i1.1484

\section{ARTICLE HISTORY}

Received: 11 January 2019

Revised: 24 February 2019

Accepted: 22 April 2019

KEYWORDS

Mental Health Learning;

Metacognitive Approach;

Counseling Guidance;

\section{ABSTRACT}

This research aims to develop learning materials for mental health which be designed by Metacognitive approach. The development model of learning materials using Research and Development (R \& D) methods who be developed by Borg and Gall and be combined with teaching development model Dick and Carey. The population for the product trials are UMSU students majoring in counseling guidance study programme. The instrument which be used is questionnaire. This products trials have three steps including personal gruops, small gruops and the field. Before products trials, the researcher does the expert validation trial for the content and design of learning materials for mental health using questionnaires according to the indicators that have been determined. Then the questionnaire be analysed to see the percentage and the validation criteria of Learning materials. The results of this research is a mental health diktat be designed used metacognitive approach.

\section{INTRODUCTION}

Mental health in counseling guidance has an important role in the efforts to recognize and detect mental health students/clients in doing counselling services. Student counseling guidance must be able to understand and explain the characteristics of behaviors that is normal or abnormal as an attempt to be able to detect a wide range of problems faced by learners. It gives mental health knowledge and understanding for students as prospective teachers in doing ministry prima against students/clients through an understanding of personal mental healthy learners in its ability to conformity with the environment and the learning process so that optimal development are achieved.

Based on the results of pra research in may 2016 towards mental health courses showed a lack of active college students at the time of the courses. In addition observationally that difficulty of learning materials found the mental health courses arranged by one of the learning approaches in the environmental education of mathematics Muhammadiyah University of North Sumatera.

Student educational counseling guidance is prospective- educators who play an active role to overcome the mental problems of students in all schools. Therefore, the role of Professor of educational counseling guidance is needed. According to the Government Regulation Number 32 Year 2013 about education standards state that the educator must have an academic qualification and competence as an agent of healthy learning, physical and spiritual, as well as have the ability to realize the the national education goals. The definition of educators as agents of learning (learning agent) is a role as a facilitator among other educators, motivators, pacemakers, and inspiring learning for learners.

To have an academic qualification and competence of students as prospective educator or teacher, then as a lecturer in fisilitator need to create learning process and learning materials. According to the regulation of the Minister of the year 2013 of national standards of higher education stated that the learning process should be implemented in an interactive, fun, challenging and motivating students to participate actively, as well as provide the opportunity to berkreativitas and independent. 
Learning materials is the part that needs to be provided in the learning process. Daries (1981) States that learning materials is a more specific learning resources containing the stages in the development of instructional, so that students can learn in accordance with their own pace based on individual needs and its capabilities. According to Yaumi (2013) that the function of learning materials in the process of learning is as a representation of the presence of the standard means of professors, the achievement of competencies and learning objectives as well as be able to optimize the service of learners.

To realize the function of these materials it is necessary to note everything that supports the success of the learning process. Yaumi (2013) stated that the need to consider the concept, types and steps in the development of learning materials. Noornia (2011) stated that the metacognitive approach in learning process can be standalone learning. In addition, according to Haryati (2012) stated that the metacognitive approach is a student-centered approach, so that students become motivated and self-directed learning process.

Based on the description of the problem and the opinions which have been expressed above, the need for the creation of learning materials courses of mental health with the metacognitive approach, which is a compiled learning materials based learning methods. Through the learning materials expected students gravitated towards mental health courses and learning process into an interactive, fun, challenging and motivating students to participate actively, as well as provide the opportunity to berkreativitas and independent. Therefore the author submits a research " The Development of Mental Health Learning Materials Using The Metacognitive Approach in Counseling Guidance Study Programme in FKIP UMSU " in the hope it can be useful as learning materials for repair the next learning.

\section{MATERIALS AND METHOD}

\subsection{Understanding Mental Health}

Mental health is a situation where a person does not experience the feeling of guilt towards himself, has estimated that relistis against himself and can receive a deficiency or weakness, the ability of the face the problems in her life, having a social life satisfaction, as well as having the happiness in her life.

The discussion in mental health involves the individual's ability to recognize good behavior characteristic of a normal abnormal or problematic in an effort to provide psychological assistance through counseling guidance services. In resolving a problem not uncommon teachers faced with unique behaviors of learners which often complicate the teachers to provide appropriate assistance to learners, but with an understanding of mental health can be make it easy for teachers to detect such behavior is making it easier for teachers provide appropriate services.

\subsection{The Metacognitive Approach}

Metacognition direct student attention approach against the relevant material and guide them to choose the right strategy to solve problems through Metacognition question like what do you understand to these problems? What strategy you need to solve the problem? What's wrong than you have done, or if this is true, then what will happen? Why are you doing so? If this way? What other way is there?. According to Fauzi (2011) Metacognition has a crucial role in designing (planning), monitoring (monitoring) as well as evaluate (evaluation) the knowledge which belonged to later developed into action (action).

Mathematical thinking habits are built through Metacognition approach is ask yourself about what it takes to solve a problem and how the process is complete. According to Jendriadi (2009) States that ask is one of the best techniques in the learning process. In addition, according to Fauzi (2011) that a given question should contain questions to herding (promting questions), digging (probing questions) and generalize (generalisation questions). Therefore, the need to bring up the question of Metacognition to college students through the learning materials to reveal their curiosity.

The habit of asking myself can direct students to build their knowledge and strategies in solving problems so that students will be aware of the cognitive ability and associate the new knowledge that is being studied. According to Scheinde and Artelt (2010) States that Metacognition has an impact on the quality of learning. In addition, Fauzi (2011) stated learning approach with Metacognition can improve communication skills and independence of one's learning.

After giving the expected presence of student Metacognition in process so it can be influential effect on the behavior of strings. According to Goos (1995) that the mathematical Metacognition process affect the behavior of a person. Therefore, the questions need to be raised at the time of Metacognition interactions processed and learning materials to encourage students to find and use strategies in solving mathematical problems. The second experiment was arranged in randomized complete block design with one factor and four replications. $\mathrm{NaCl}$ treatment applied to perform salinity stress condition in four concentrations: 0 ppm, 1500 ppm, 3000 ppm, and 4500 ppm.

\subsection{Research Method}

The research method used is research development (developmental research). According to Borg and Gall (1983), approach to Research and Development (R D \&) in education includes several steps, namely:

1. Conduct an analysis of the problem and the need to collect information in the form of mental health literature review, determine the SAP and specify the learning objectives.

2. Do product planning/mental health learning materials and manufacture of instruments in the form of the 
now about the quality of learning materials as seen from the component material, presentation and language.

3. Drafting mental health learning materials with the metacognitive approach.

4. Validate expert by using question form validation. Do a revision of the main product, based on feedback and suggestions from the results of validation experts.

5. Do a revision of product from the results of the validation assessment expert

6. Test materials (products) against a small group of individuals, and the field in Muhammadiyah University of North Sumatera students that have characteristics of low ability students, going through the now (questionnaire) is given.

7. The final result, is a product of the numerical method of learning materials that are already completed revised and ready to be applied to learning.

\subsubsection{Stage Learning Material Testing (Products)}

\subsubsection{Research Design}

The design of the research consists of several stages: a) Validation experts; design validation of learning; c) revision of the development based on the assessment of 2 expert content and 2 expert instructional design approach to Metacognition (phase I trials); d) test materials by 5 students (individual test) and 10 students (small group trials); e) revision of the product (test phase II); f) field trials against students; revision g) products (phase III trials).

\subsubsection{The Subject of Research}

The subject of the trial is a user of the product i.e. four semester Student Education Counseling at the Muhammadiyah University of North Sumatera.

\subsubsection{Implementation Research}

Implementation of test run through three stages, namely:

\section{Individual trials.}

In this step learning materials have been revised based on the advice of some experts. Now the assessment given to the users individually with the purpose to find out the validity of the product after repair expert content and design team. Inputs from individual trials subsequently used as the basis to conduct the repair of product.

\section{Small group trials.}

This test to find out if there are shortcomings that need to be repaired from the product after the revision of the experts and trial of individuals. If there is a shortage of it will be done a revision.

\section{Field trials}

This test is done to find out if there are still deficiencies that need to be repaired from the learning materials developed after discussions with team of experts and the results of a test group of individuals and small groups.

\section{RESULTS AND DISCUSSION}

Research results on this research in the form of mental health learning materials with Metacognition approach, with regard to the results obtained in this study and learning materials are designed. Competences of the intertwined and support the achievement of the purposes of the mental health public lecture, as illustrated in the following diagram.

TIU: After studying the mental health of students was expected to have a healthy personal and dynamic in carrying out counselling services.

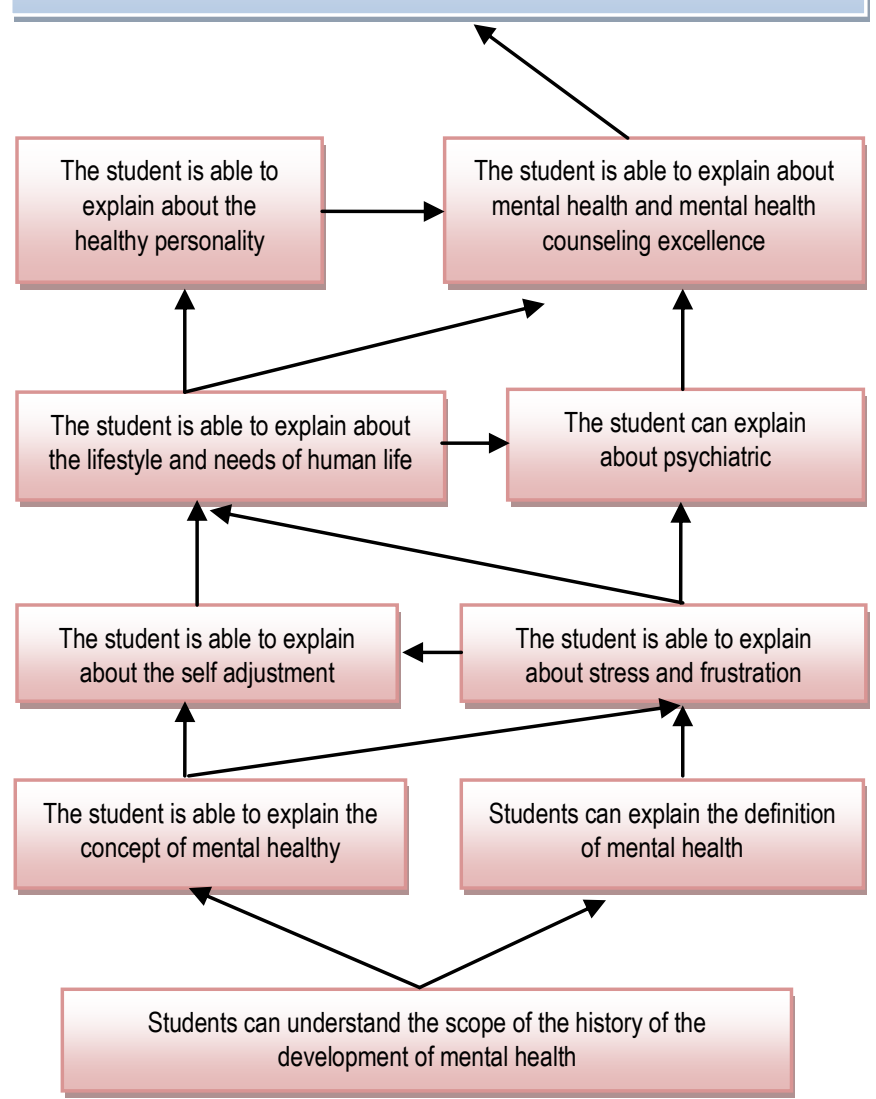

Based on its syllabus and SAP are made then retrieved a Mental Health learning materials. The following products from materials that are designed.

1. The initial Discussion Stage

Before we learn about the material in chapter I of this, please note the following problems. 


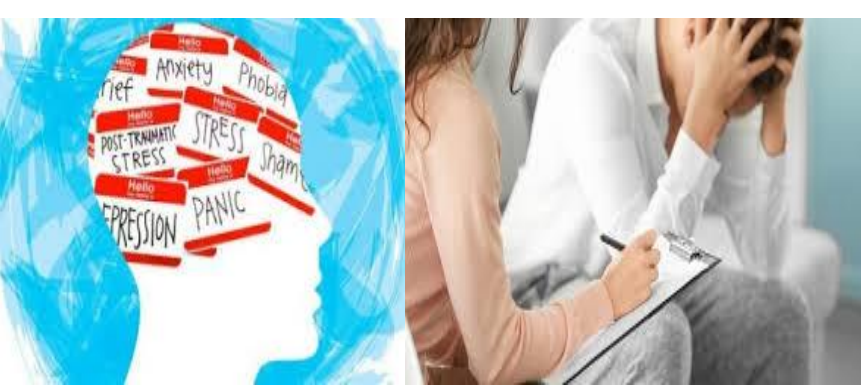

Look at the picture (1) and (2).

What do you think happens to the second image above?

To answer the question above. What should you do? Understanding what you should know before completing the problem? How do you solve the problem?

2. The Stage of Independence

Working on a matter under these's ascetic effort.

What you know with mental health?

Mentioned the example of unhealthy mental?

To answer the question above. What should you do? Understanding what you should know before completing the problem? How do you solve the problem? Check back your answers.

Before answering the above question please learned the material provided under this.

In counseling guidance, services provided in normal individuals who are facing issues in professional (scientific, systematic, measurable and confidential).

Mental health in counseling guidance has an important role in the efforts to recognize and detect mental health students/clients in doing the counseling. It gives mental health knowledge and understanding for the counselors in conducting services against primed learners/ client through an understanding of learners/private clients who are mentally healthy in its ability to self adjustments with the environment and the learning process so that optimal development are achieved.

Through this understanding, it is hoped the Counselor can tell which normal clients are problematic could be handled and where clients who have experienced mental health problems should be referred to a psychologist or psychiatrist.

Prior to know more about mental health it's good we know the history of the development of mental health.

\section{History Development of Mental Health}

Mental health is at first less attention as well as medicine because it is less mental problems can be observed and seen as much as physical ailments relative is more easily detected. Mental health problems is actually a lot happened in the middle of the community, but due to the limitations of knowledge regarding behaviors that indicate a mental disorder so as to behavior-behavior that is considered uncommon. This also resulted in a lack of sensitivity towards community mental health problems, so often those who experience mental disorders do not get the proper help. Cultural factors also affect a diverse view of society regarding the sufferers of mental disorders.

History shows that the issue of mental health has existed since prehistoric times. A discovery on the stone age, 500 thousand years ago, showed a healing method called Trephening which is a method of operation that is performed with equipment from the rocks, where healers opened part of the skull for the purpose allow the evil spirits out disorders penimbul.

With the growing of human civilization, then your views on mental health was also undergoing changes. Here is the history of the development of mental health:

\section{Mental disorders are not considered sick}

\section{The year 1600 and earlier}

The view of society that assumes that people who experience mental disorders is because they are possessed by a demon (God/demon) that exists around them. Generally found in China, Egypt, Greece, and Jewish. In the Bible also discovered a method of exorcism (exorcise) of the human body.

The philosophers at that time thought of demonology rejected the idea as a cause of mental disorders. Hipocrates (460-377 BC) a doctor who believes Greece mental disorders caused by natural causes and pathology of the brain. Hipocrates trying to find the cause of physical disorders by dividing into three groups, namely the Mania, Melancholia and Phrentis (brain fever). Plato (429-347SM) conduct studies against individuals who commit criminal activities in mental condition are plagued with a fringe term Insanity (madness), namely the inability of a person to account for his actions. Aristotle (384-322SM) argued that the mental disorder caused body fluids that are not balanced. Galen (130-200SM) a doctor who studied the nervous system and divide the causes of mental disorders into the physical and mental aspects. Avicena/Ibn Sinna (980-1037) physician who developed the principle of humanistic treatmen when the Western world act differently.

This breakthrough backward in the middle ages where people back on understanding demonology exorcise method so that it is widely used by the theologian though ineffective.

\section{The year 1692}

At the time this happened the pursuit against a lot of people are indicted as a witch in League with the devil. Review existing records indicate it turns out they are actually people who showed symptoms that resemble a mental disorder sufferers so that their lives seem strange and different from others. This was opposed by Demonology opinion Paracelsius who understand the mania of dancing as a form of interference with paying attention to aspects of the psychic sufferers and Terese of Avila who posited mind (mind). 
In the $16^{\text {th }}$ century was built the shelter institution the individual impaired and unable to take care of himself as well as distanced from society, called the Assylum. In London (King Henry VIII) makes the Abbey of St. Mary of Bethlehem became Bedlam Hospital. The condition of Assylum that time very inhuman where sufferers of caged and chained at the wall and on the bed.

\section{Mental disorders are considered as ill}

\section{The year 1724}

The Reverend Cotton Mather (1663-1728) break the superstition that live in the community with regard to mental illness with advancing the physical explanation regarding mental illness. At this time the medical approach to the start was introduced to give an explanation of the problem as a result of psychiatric disorders that occur in the body.

A French physician, Philipe Pinel (1745-1826) using the humanistic approach to solve the problem of mental illness. In the hospital, his patients no longer chained, tied to the wall and the bed. Pinel took care of them as sick people and not like wild animals. They brought the streets around the hospital. Finally, among them many are successful, they no longer shows a tendency to injure or damage itself. Pinel believed patients who treated him is basically a normal human that must be approached with patience and understanding and to be treated as human beings who have no self esteem.

Dorothea Dix (1802-1887), promote the humane handling on the sick soul, by establishing many public psychiatric hospitals.

\section{The year 1812}

Changes in attitude and way of treatment of mental disorders occur when the development of abnormal psychology and Psychiatry in America in 1783. When that Benjamin Rush (1745-1813) was a lawyer who became a member of the medical staff at the hospital Pensylvania. In hospitals there are 24 patients who considered lunatics (people are crazy or sick memories). At that time very little knowledge about the cause and how to cure the disease. As a result patients confined in an enclosed space, and they never washed down with water. Rush performs a very useful effort to understand those who suffer from mental disorders through writing articles. One of them is titled "Medical Inquiries and Observations Upon the Diseases of the Mind". Continuously, Rush hold the treatment to patients by providing the impetus (motivation) to want to work, recreation, and looking for fun.

Years of 1830-1860 in the United Kingdom appears Therapeutic optimism in dealing with mental patients. At that time the growing belief that the handling in a mental hospital is the right thing and the scientific method to cure insanity. But because many fail then appear Therapeutic pessimism that was influenced by socialism Darwin that States that evolution is the development of mental disorders so it is innate and not possible anymore.

\section{The year 1908}

In 1909, the mental Hygiene movement formally began to appear. Development of the mental hygiene movement is a service of Clifford Whitting Beers (1876-1943) and his book "A Mind That Found it Self" which is his experience as a mentally ill patient care agencies and cruelty, even because in spite of it he crowned as The Founder of the Mental Hygiene Movement. He was famous for her experiences in the field of prevention and treatment of mental disorders in a very humane.

By law, the mental hygiene movement gained recognition on July 3, 1946, in which the President of the United States signed The National Mental Health Association, which contains a long term program that is directed to improving the health mentally the whole citizens.

\section{Several objectives contained in the document include:}

a) Improves the mental health of the entire United States citizens, through research, investigations, experiments, serving cases, diagnosis, and treatment.

b) Helps government agencies and private entities that undertake research activities and improve coordination between researchers in conducting and applying research results.

c) Provide exercise against its personnel about mental health.

d) Developed and help in applying various methods of prevention, diagnosis, and treatment of the people with mental disorder.

\section{The year $1940 s$}

Elektrotherapi was first used in America against the patient's mental illness.

\section{The year $1950 \mathrm{~s}$}

In 1950, the Organization of mental hygiene continues to grow, with the founding of the National Association for Mental Health. The mental hygiene movement continued to thrive until the year 1975 in America there are more than a thousand gathering of mental health. In other parts of the world, this movement developed through The World Federation for Mental Health and The World Health Organization.

\section{The year 1952-1960s}

Conventional antipsychotic drugs (chlorpromazine) is used for patient schizoprenia and other major mental disorders.

\section{CONCLUSION}

This research resulted in the form of the syllabus and SAP, as well as Mental Health learning materials designed by the metacognitive approach. Great expectations of researchers so that these materials can be used in learning, especially Mental health courses. 


\section{REFERENCES}

Borg. W.R. and Gall, M.D. (1987). Educational Reaserch: An Introduction. London: Longman, Inc.

Daries, I. (1981), Instructional Tenchnology and Media, MC Graw Hill Company, Newyork

Fauzi. A. (2011). Mathematical Connections upgrade and independence student learning with the learning metacognitive approach in junior high school. Dissertation on PPS UPI: not published.

Goos, M. (1995).Metacognitive Knowledge, Belief, and Classroom Mathematics. Eighteen Annual Conference of The Mathematics Education Research Group of Australasia, Darwin, July 7-10 1995.

Haryati, Feri. (2012). Improved Problem-Solving Ability And Independence Of Learning Through Metacognition-Based Approach To Learning Soft Skills. Thesis on PPs UPI: not published

Munir, Renaldi. (2013). Numerical Methods. Bandung: Informatics, Bandung.

Noornia, Anton. (2011). Cooperative Learning with Metacognitive Approach Ton Enhance Mathematical Critical Thinking And Probelem Solving Ability And the Relation To Self Regulated Learning. Journal Of International Seminars and the 4th National Conference on Mathematics Education. Juni 2011

Novaliyosi. (2011). Improve Critical Thinking Mathematically And Independence Through Learning With Student Learning Approach To The Investigation. Thesis on PPs UPI: not published.

Presiden RI .(2013). Government regulation of the Republic of Indonesia Number 32 Year 2013 About education standards.

Schneider, W. \& Artelt, C. (2010). Metacognition and mathematics education. ZDM -The International Journal on Mathematics Education 42(2): 149-161.

Sianifar, R.H. (2013). Matlab Programming. Bandung: Sianifar, R.H. (2013). Matlab Programming. Bandung: Informatics Bandung

Sutikno, Sobry. (2013). Learning and learning. Lombok: Holistica

Yaumi, Muhammad. (2013). Principles of Instructional Design. Jakarta: Kencana. 